\title{
Estrogen Monotherapy and Combined Estrogen-Progestogen Replacement Therapy Attenuate Aortic Accumulation of Cholesterol in Ovariectomized Cholesterol-fed Rabbits
}

\author{
Jens Haarbo, Per Leth-Espensen, * Steen Stender, ${ }^{*}$ and Claus Christiansen \\ Department of Clinical Chemistry, University of Copenhagen, Glostrup Hospital, 2600 Glostrup; and ${ }^{*}$ Department of Clinical Chemistry, \\ University of Copenhagen, Rigshospitalet, 2100 Copenhagen, Denmark
}

\begin{abstract}
Cardiovascular disease is currently the leading cause of death among women in the United States. To investigate the effect of postmenopausal hormone therapy on atherogenesis, we studied 75 cholesterol-fed female rabbits for 19 wk. The rabbits were randomly assigned to five groups. Four groups underwent bilateral ovariectomy followed by treatment with either $17 \beta$-estradiol, $17 \beta$-estradiol plus norethisterone acetate, $17 \beta$-estradiol plus levonorgestrel, or placebo. The fifth group had a sham operation and received placebo. The hormone groups had only one-third of the aortic accumulation of cholesterol found in the placebo groups, a difference that was highly statistically significant $(P<0.0001)$. No significant differences in aortic accumulation of cholesterol were found in the hormone groups. This indicates that estrogen attenuates atherogenesis in cholesterolfed ovariectomized rabbits and that two commonly prescribed progestogens do not counteract the effect. The beneficial effect of estradiol could only partly be explained by its lowering effects on serum total cholesterol or VLDL cholesterol, which implies that estradiol possesses additional beneficial effects, possibly a direct action on the arterial wall. (J. Clin. Invest. 1991. 87:1274-1279.) Key words: atherogenesis • aorta • hormone $\bullet$ lipids 17 -estradiol
\end{abstract}

\section{Introduction}

Cardiovascular disease is currently the leading cause of death and disability in Western societies, accounting for close to 500,000 deaths in women in the United States yearly (1). Certain epidemiological characteristics of cardiovascular disease indicate that endogenous estrogen has some protective effect. For instance, the male-to-female ratio of cardiovascular disease peaks around the menopause and then gradually declines (2), and the risk of cardiovascular disease is increased in ovariectomized women (3) and postmenopausal women (4) compared with that of age-matched menstruating women.

Several epidemiological studies suggest that estrogen replacement therapy reduces the incidence of cardiovascular disease, which partly may be explained by changes in the serum

Address correspondence and reprint requests to Jens Haarbo, Department of Clinical Chemistry, University of Copenhagen, Glostrup Hospital, DK-2600 Glostrup, Denmark.

Received for publication 27 August 1990 and in revised form 5 December 1990.

J. Clin. Invest.

(C) The American Society for Clinical Investigation, Inc.

0021-9738/91/04/1274/06 \$2.00

Volume 87, April 1991, 1274-1279 concentrations of lipoproteins $(5,6)$. Estrogen monotherapy is associated with a two- to threefold increase in the risk of endometrial neoplasia, which seems to be eliminated or reduced by the addition of a progestogen (7). Some progestogens, however, seem to counteract the potential beneficial effects of estrogen on serum concentrations of lipids and lipoproteins (8). Combined hormone replacement therapy is prescribed for millions of postmenopausal women, yet its effect on the incidence of cardiovascular disease is largely unknown.

As randomized prospective studies of the impact of combined hormone replacement therapy on cardiovascular disease are unfeasible in humans, animal studies may be of considerable interest. Previous studies have indicated that estrogen may retard cholesterol accumulation in rabbit aortas (9-12). The aim of the present study was therefore to investigate the influence and mechanisms of combined hormone replacement therapy and estrogen monotherapy on the accumulation of cholesterol in the aortas of ovariectomized, cholesterol-fed rabbits.

\section{Methods}

Study design. 75 sexually mature and virginal female white rabbits of the Danish Country strain, obtained from Statens Serum Institute, Copenhagen, were housed in the Panum Institute, University of Copenhagen. The rabbits, which previously had been fed standard commercial rabbit chow, were housed individually in stainless-steel cages in a room temperature of $20 \pm 2^{\circ} \mathrm{C}, 50 \pm 10 \%$ humidity, and a 12 -h light cycle

The 75 rabbits were fed a diet containing $0.1 \mathrm{~g}$ cholesterol/day for the first $7 \mathrm{wk}$ (Fig. 1). In week 3 , they were anesthetized with $0.4 \mathrm{ml} / \mathrm{kg}$ Hypnorm ( $0.2 \mathrm{mg}$ Fentanyl $+10 \mathrm{mg}$ Fluanizon per ml, Janssen Pharmaceudica N.V., Beerse, Belgium) injected intramuscularly and randomized to either bilateral ovariectomy (60 rabbits) or exploratory laparotomy, where the ovaries were localized (15 rabbits) (13). At the end of week 5 , the 60 ovariectomized rabbits were randomized to four groups, each of 15 rabbits, to receive daily treatment with either $4 \mathrm{mg} 17 \beta$ estradiol $\left(E_{2}\right),{ }^{1} 4 \mathrm{mg} 17 \beta$-estradiol plus $1 \mathrm{mg}$ norethisterone acetate $\left(E_{2} / \mathrm{NETA}\right), 4 \mathrm{mg} 17 \beta$-estradiol plus $0.5 \mathrm{mg}$ levonorgestrel $\left(\mathrm{E}_{2} / \mathrm{LNG}\right)$ or no hormones (designated placebo) (O-PLA). The 15 rabbits that had undergone the sham operation received placebo (S-PLA). At the beginning of week 8 , the dietary amount of cholesterol was raised for all the rabbits to $0.32 \mathrm{~g}$ per rabbit/d.

Rabbit chow. All the rabbits were daily fed $80 \mathrm{~g}$ of chow, which consisted of hormones (Schering AG, Berlin, FRG) or placebo, corn oil $6.4 \mathrm{~g}$ (BP80, Mecobenzon, Copenhagen), cholesterol 0.1-0.32 g (USP; Sigma Chemical Co., St. Louis, MO), and standard rabbit pellets (Superfoss, Denmark).

1. Abbreviations used in this paper: ANOVA, analysis of variance; $\mathrm{E}_{2}$, $17 \beta$-estradiol; $E_{2} /$ LNG, $17 \beta$-estradiol plus levonorgestrel; $E_{2} / N E T A$, $17 \beta$-estradiol plus norethisterone acetate; IDL-C, intermediate density lipoprotein cholesterol; O-PLA, ovariectomized placebo-fed rabbits; S-PLA, sham-operated placebo-fed rabbits; TC, total cholesterol; TG, triglyceride. 

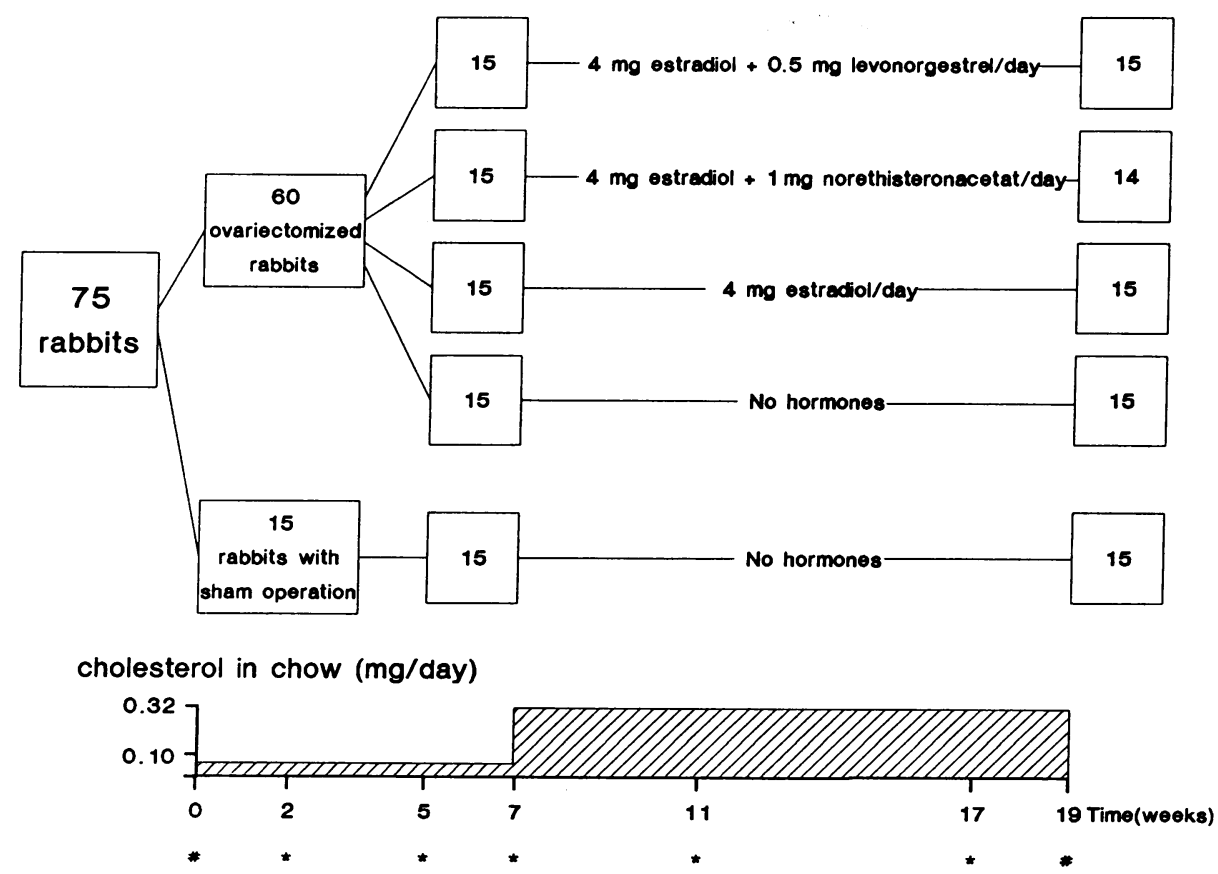

Figure 1. The 19-wk study period. The cholesterol content in the chow and the hormone replacement therapies are given. (\#) Measurement of serum lipids (total cholesterol and triglycerides) and (*) lipids and lipoproteins, respectively.

To prepare the chow, the cholesterol and half the corn oil were heated until the cholesterol had completely dissolved, and then mixed thoroughly with the standard rabbit pellets. The hormones (or placebo) were dissolved in ethanol and poured into the remaining corn oil. After the ethanol had evaporated, this was mixed thoroughly into the cholesterol containing chow. The chow for the placebo groups did not include hormones, but was otherwise prepared exactly as the chow given to the three hormone groups. Chow was prepared for $1 \mathrm{mo}$ at a time and stored in darkness at $-20^{\circ} \mathrm{C}$. The rabbits had free access to water.

Serum lipids. Three aliquots from the serum samples obtained at week $2,5,7,11$, and 17 were adjusted to a density of $1.006,1.019$, and $1.063 \mathrm{~g} / \mathrm{ml}$, respectively, and centrifuged at $4^{\circ} \mathrm{C}$ at $1.58 \times 10^{8} \mathrm{~g} \times$ min in a 50.4 Ti rotor (Beckman Instruments, Inc., Fullerton, CA). Top and bottom fractions were obtained after tube slicing. The cholesterol content in the aliquots of whole serum and the ultracentrifuged fractions was determined by an enzymatic method. Serum triglycerides (TG) were determined using an enzymatic method (Chem I; Technicon Instruments Corp., Tarrytown, NY). Blood samples were taken $24 \mathrm{~h}$ after the last feed.

Hormone assays. Estradiol and norethisterone were measured as previously described, except that tert-butyl methyl ether was used for the extractions (14). The sensitivity of the estradiol assay was 0.01 $\mathrm{nmol} /$ liter and the intra- and interassay imprecisions expressed as coefficients of variations were 9 and $18 \%$. The norethisterone assay had a sensitivity of $0.3 \mathrm{nmol} /$ liter and intra- and interassay imprecisions of 5 and $8 \%$. The levonorgestrel assay had a sensitivity of $0.2 \mathrm{nmol} / \mathrm{liter}$ and intra- and interassay imprecisions of 7 and $10 \%$.

Aortic tissue. At the end of the experiment, the rabbits were anesthetized with intravenous injections of a pentobarbital $5 \%$ solution. The thoracic aorta was dissected free and the adventitia was carefully removed under running saline. The aorta was opened longitudinally and the surface rinsed with saline. The vessel was fixed with pins on a corkboard, and the tissue was divided into proximal and distal parts at the level of the first intercostal arteries. From each of these parts, the inner layer containing the intima and part of the media was stripped from the underlying outer media, and all four parts were weighed. The tissues were stored within $1 \mathrm{~h}$ at $-20^{\circ} \mathrm{C}$ until analyzed.

The aortic tissue was minced, and the lipids were extracted with chloroform and methanol (2:1, vol/vol) over $24 \mathrm{~h}$. Lipids and proteins were separated (15) and the total cholesterol in the four tissue specimens was determined by the Liebermann-Burchard method. Free and esterified cholesterol were separated by thin-layer chromatography and eluted from the silica gel; values were determined by the LiebermannBurchard method after saponification. The amount of protein in the tissue specimens was determined by the method of Lowry et al. (16) after extraction of the lipids and digestion of the residue for $24 \mathrm{~h}$ with 5 $\mathrm{M} \mathrm{NaOH}$.

Endometrial tissue. Endometrial tissue was frozen immediately on solid carbon dioxide and stored at $-85^{\circ} \mathrm{C}$ until analyzed. The biochemical analyses were performed with a modification of previously described methods $(17,18)$. The interassay imprecisions (CV) for estradioldehydrogenase and isocitratedehydrogenase were 14 and $2 \%$, respectively. The DNA content of the endometrial tissues was measured according to the method of Burton (19). The interassay imprecision (CV) was $15 \%$.

Statistics. Analysis of variance (ANOVA) was used to test for statistically significant differences between the five groups with regard to age, body weight, food intake, gain in body weight, serum lipids and lipoproteins, activities of endometrial estradioldehydrogenase and isocitratedehydrogenase, and aortic accumulation of cholesterol. The data on aortic cholesterol, estradioldehydrogenase, and isocitratedehydrogenase activities were logarithmically transformed to normalize variations. If ANOVA indicated significant differences between groups, Students's $t$ test was used to test each treatment with all others. The relation between the aortic content of esterified and total cholesterol as well as the relation between the total cholesterol content of the four parts of the aorta were analyzed by calculation of parametric coefficients of correlation. The two-by-two analysis (selected on the same serum total cholesterol or VLDL-C) was investigated by Student's $t$ test for unpaired data. Analysis of covariance (ANOCOVA) was used to examine the independent effects of serum lipids, lipoproteins, and hormone treatment on aortic accumulation of cholesterol. All analyses were performed using the Statistical Analysis System (20).

\section{Results}

No differences in age, body weight, total food intake, gain in body weight, or initial serum lipids and lipoproteins were seen between the five groups (Table I). One rabbit in the $E_{2} /$ NETA group had to be killed in week 9 , because of a fractured lumbar vertebra, which left 74 rabbits in the study. 
Table I. Baseline Characteristics, Body Weight Gain, and Total Food Intake (mean \pm SD)

\begin{tabular}{lccccc}
\hline & S-PLA & O-PLA & $E_{2}$ & E $/$ NETA & E $_{2} /$ LNG \\
\hline Age $(w k)$ & $30.7 \pm 5.9$ & $28.7 \pm 3.0$ & $30.2 \pm 4.4$ & $28.5 \pm 3.4$ & $29.1 \pm 5.9$ \\
Body weight $(k g)$ & $4.06 \pm 0.5$ & $3.74 \pm 0.3$ & $4.06 \pm 0.5$ & $4.05 \pm 0.3$ & $3.87 \pm 0.4$ \\
TC $($ mmol/liter $)$ & $1.52 \pm 0.4$ & $1.42 \pm 0.4$ & $1.49 \pm 0.5$ & $1.74 \pm 0.6$ & $1.46 \pm 0.4$ \\
TG $($ mmol/liter $)$ & $0.76 \pm 0.2$ & $0.93 \pm 0.4$ & $0.97 \pm 0.5$ & $0.98 \pm 0.5$ & $0.80 \pm 0.3$ \\
HDL-C $($ mmol/liter $)$ & $0.65 \pm 0.1$ & $0.67 \pm 0.2$ & $0.55 \pm 0.2$ & $0.56 \pm 0.1$ & $0.66 \pm 0.1$ \\
Body weight gain $(k g)$ & $0.03 \pm 0.3$ & $0.12 \pm 0.3$ & $0.01 \pm 0.3$ & $0.09 \pm 0.4$ & $0.04 \pm 0.4$ \\
Total food intake $(k g)$ & $10.4 \pm 0.3$ & $10.5 \pm 0.3$ & $10.3 \pm 0.3$ & $10.2 \pm 0.5$ & $10.4 \pm 0.3$ \\
\hline
\end{tabular}

There were no significant differences in these parameters between any of the five groups (ANOVA, nonsignificant in all cases). Cholesterol, 1 $\mathrm{mmol} /$ liter $=38.6 \mathrm{mg} / \mathrm{dl}$; triglyceride, $1 \mathrm{mmol} / \mathrm{liter}=88.5 \mathrm{mg} / \mathrm{dl}$.

Table II shows the mean concentration (adjusted for baseline differences) of serum total cholesterol (TC) during the experimental period (calculated as the area under the curve, divided by the duration of the experimental period in days) and the distribution of that cholesterol between the different lipoprotein fractions. Mean serum TC, very low density lipoprotein cholesterol (VLDL-C), and intermediate density lipoprotein cholesterol (IDL-C) were generally significantly higher in the two placebo groups than in the $E_{2}$ and the $E_{2} / N E T A$ groups, which in turn were significantly higher than in the $E_{2} /$ LNG group $(P<0.0001)$. No statistically significant differences in serum low density lipoprotein cholesterol were seen.

Table III gives the hormone levels in the five groups, measured in week 17. In addition, the serum concentrations of estradiol and progestogen were measured in week 15 after an overnight fast and 3,10 , and $22 \mathrm{~h}$ after feeding in a subgroup ( $n$ $=25$ : five rabbits randomly selected from each of the five groups) to investigate the pharmacokinetics of these hormones. The elimination half-lives for norethisterone and levonorgestrel were $\sim 6.5 \mathrm{~h}$ and $10.5 \mathrm{~h}$, respectively. The rabbits receiving exogenous estradiol had significantly higher levels of serum estradiol $3 \mathrm{~h}$ after being fed with the hormone containing chow than the placebo rabbits $(P<0.0001)$. Table IV shows the activities of endometrial estradioldehydrogenase and isocitratedehydrogenase in proportion to the DNA content of the endometrial tissue. The rabbits receiving estradiol monotherapy had significantly higher levels of estradioldehydrogenase than those receiving estradiol and progestogen, which in turn had significantly higher levels than the two placebo groups (In all cases: $P<0.01$ ).

Fig. 2 visualizes the accumulation of cholesterol in the inner proximal layer of the thoracic aorta. The groups fed hormones had only accumulated one-third of the cholesterol seen in the placebo groups, a difference that was highly statistically significant $(P<0.0001)$. The aortic content of esterified cholesterol was highly significantly related to the total cholesterol content $(r=0.97, P<0.0001)$, and the total cholesterol content of the four parts of the aorta was highly significantly interrelated (in all cases: $r>0.60, P<0.0001$ ).

To investigate the effect of estradiol on aortic cholesterol accumulation, independently of the effect on serum total cholesterol, we selected pairs of rabbits $(n=15)$ from the hormone groups $\left(E_{2}, E_{2} / N E T A, E_{2} / L N G\right)$ and placebo groups (S-PLA, O-PLA) that had the same serum cholesterol concentrations: $16.3 \pm 0.7 \mathrm{mmol} /$ liter and $16.2 \pm 0.8 \mathrm{mmol} / \mathrm{liter}($ mean $\pm \mathrm{SEM}$ ), respectively. The hormone subgroup had significantly lower concentrations of aortic cholesterol than had the placebo subgroup (Fig. $3 a)(P<0.01)$. Fig. $3 b$ visualizes a similar comparison, where the pairs of rabbits $(n=15)$ from the estradiol and placebo groups were selected on their similarity of serum VLDL-C concentrations $(6.4 \pm 0.4 \mathrm{mmol} / \mathrm{liter}$ and $6.3 \pm 0.5$ $\mathrm{mmol} /$ liter). The hormone subgroup had significantly less aortic cholesterol accumulation than the placebo subgroup $(P$ $<0.05)$. Analyses of covariances relating aortic cholesterol accumulation (logarithmically transformed) to treatment groups with mean TC (or mean VLDL-C) as covariates showed that

Table II. Serum Total Cholesterol and the Distribution of that Cholesterol between the Lipoproteins in the Five Groups of Rabbits (mean \pm SEM)

\begin{tabular}{|c|c|c|c|c|c|c|}
\hline & S-PLA & O-PLA & $E_{2}$ & $\mathrm{E}_{2} / \mathrm{NETA}$ & $\mathrm{E}_{2} / \mathrm{LNG}$ & ANOVA \\
\hline $\mathrm{TC}(\mathrm{mmol} / \mathrm{liter})$ & $12.9 \pm 1.0$ & $16.3 \pm 1.6$ & $10.9 \pm 1.1^{ \pm 1}$ & $8.9 \pm 1.1^{* \neq}$ & $6.3 \pm 0.8^{* \neq 8}$ & $P<0.0001$ \\
\hline VLDL-C (mmol/liter) & $6.8 \pm 0.6$ & $10.3 \pm 1.7$ & $4.5 \pm 0.7^{* \pm 1}$ & $4.1 \pm 0.7^{* \neq 1}$ & $1.9 \pm 0.4^{* \neq 511}$ & $P<0.0001$ \\
\hline IDL-C (mmol/liter) & $3.1 \pm 0.2$ & $3.6 \pm 0.2$ & $3.0 \pm 0.2^{\ddagger 1}$ & $2.3 \pm 0.3^{* \pm 1}$ & $1.4 \pm 0.2^{* \neq 511}$ & $P<0.0001$ \\
\hline LDL-C (mmol/liter) & $2.3 \pm 0.3$ & $2.4 \pm 0.4$ & $3.3 \pm 0.3$ & $2.5 \pm 0.4$ & $2.4 \pm 0.3$ & NS \\
\hline HDL-C (mmol/liter) & $-0.20 \pm 0.03$ & $-0.17 \pm 0.03$ & $-0.19 \pm 0.05$ & $-0.18 \pm 0.04$ & $0.00 \pm 0.09^{*}$ & $P<0.05$ \\
\hline TG (mmol/liter) & $0.22 \pm 0.06$ & $0.33 \pm 0.08$ & $0.09 \pm 0.04^{\ddagger}$ & $0.01 \pm 0.04^{* \neq}$ & $0.08 \pm 0.09^{\ddagger}$ & $P<0.01$ \\
\hline
\end{tabular}

Values are given as the mean concentration (area under curve) adjusted for prerandomization values. (Cholesterol, $1 \mathrm{mmol} / \mathrm{liter}=38.6 \mathrm{mg} / \mathrm{dl}$; triglyceride, $1 \mathrm{mmol} /$ liter $=88.5 \mathrm{mg} / \mathrm{dl}) .{ }^{*}$ Statistically significant $(P<0.05)$ different from the S-PLA group. Statistically significant difference from the ${ }^{\ddagger} \mathrm{O}-\mathrm{PLA},{ }^{8} \mathrm{E}_{2},{ }^{\mathrm{N}} \mathrm{E}_{2} / \mathrm{NETA}$, and ${ }^{\prime} \mathrm{E}_{2} / \mathrm{LNG}$ groups. 
Table III. Serum Hormone Concentrations at Week 17 in the Five Groups, 24 h after Feeding

\begin{tabular}{|c|c|c|c|c|c|}
\hline & Week 17 & $T=0 \mathrm{~h}$ & $T=3 \mathrm{~h}$ & $T=10 \mathrm{~h}$ & $T=22 \mathrm{~h}$ \\
\hline \multicolumn{6}{|c|}{ Estradiol (pmol/liter) } \\
\hline S-PLA & $104(32)$ & $152(50)$ & $116(21)$ & $105(23)$ & $117(27)$ \\
\hline O-PLA & $64(8.6)$ & $74.4(23)$ & $87.8(18)$ & $63.4(9.0)$ & $69.8(13)$ \\
\hline $\mathrm{E}_{2}$ & $148(43)$ & $166(49)$ & $298(59)$ & $137(40)$ & $156(51)$ \\
\hline $\mathrm{E}_{2} / \mathrm{NETA}$ & $118(35)$ & $159(41)$ & $330(17)$ & $135(32)$ & $137(43)$ \\
\hline $\mathrm{E}_{2} / \mathrm{LNG}$ & $88(15)$ & $149(43)$ & 394 (113) & $110(34)$ & $82.6(11)$ \\
\hline \multicolumn{6}{|c|}{ Norethisterone ( $\mathrm{nmol} /$ liter $)$} \\
\hline $\mathrm{E}_{2} / \mathrm{NETA}$ & $1.2(0.1)$ & $1.3(0.2)$ & $20.0(2.8)$ & $5.6(0.8)$ & $1.5(0.1)$ \\
\hline \multicolumn{6}{|c|}{ Levonorgestrel ( $\mathrm{nmol} /$ liter) } \\
\hline $\mathrm{E}_{2} / \mathrm{LNG}$ & $1.0(0.2)$ & $1.5(0.1)$ & $5.4(0.7)$ & $3.6(0.5)$ & $1.6(0.2)$ \\
\hline
\end{tabular}

Serum hormone values measured before feeding $(0)$ and at 3,10 , and $22 \mathrm{~h}$ after feeding chow in randomized subgroups $(n=5)$ from each of the five groups in week 15 . Mean (SEM). Estradiol, $1 \mathrm{pmol} / \mathrm{liter}=27.2 \mathrm{pg} / \mathrm{dl}$; norethisteron, $1 \mathrm{nmol} / \mathrm{liter}=29.8 \mathrm{ng} / \mathrm{dl}$; levonorgestrel, $1 \mathrm{nmol} / \mathrm{liter}$ $=31.2 \mathrm{ng} / \mathrm{dl}$.

the treatments in themselves had significantly independent predictive value (Fig. 3, $c$ and $d)(P<0.001)$.

\section{Discussion}

The principal findings of our study were that orally administered estradiol significantly attenuates aortic accumulation of cholesterol in cholesterol-fed ovariectomized rabbits and that the continuous addition of the 19-nortestosterone derivatives, levonorgestrel, or norethisterone, did not counteract this beneficial effect.

The hormone doses given orally to the rabbits may appear rather high, but all the rabbits seemed to be healthy except the one that had to be killed prematurely. No differences were seen between the groups in body weight gain or total food intake, which suggests that the applied hormone doses were nontoxic. No significant differences in serum estradiol level were found between the five groups $24 \mathrm{~h}$ after administration of the chow, but $3 \mathrm{~h}$ after administration the hormone treatment groups had significantly higher levels compared to the placebo groups. The group receiving estrogen monotherapy, furthermore, displayed physiological evidence of an estrogenic action on the endometrium. The estradiol and progestogen levels as well as the pharmacokinetic profile were comparable to those found in women receiving postmenopausal hormone replacement therapy (14, 21 ). In the present study both the progestogens exerted significant effects on the endometrium, which implies that the doses given produced physiological effects.

The estradiol replacement therapy significantly reduced the concentrations of serum total cholesterol, VLDL-C, and IDL-
$\mathrm{C}$, a beneficial effect that was underlined by the less atherogenic lipid and lipoprotein profile in the placebo group with the sham operation than in the ovariectomized placebo group. These findings are in accordance with previous findings in humans (22). The continuous addition of levonorgestrel to the estradiol replacement therapy induced a significant decrease in serum TC, VLDL-C, and IDL-C. It is well known that some progestogens possess estrogenic properties, which in part may explain the additional benefits conferred by progestogens on serum lipids. There were no significant differences in LDL-C between the groups. This is in accordance with previous findings (23), showing that LDL becomes "saturated" with cholesterol in cholesterol-fed rabbits, and that further increase in serum cholesterol accumulates in the VLDL fraction. Estradiol did not increase the concentration of HDL-C as seen in women. This difference may partly be explained by enhanced clearance of apolipoprotein E containing HDL particles via the LDL-receptor in rabbits (24).

Apart from the effects on serum lipid and lipoprotein levels, which may be due to induction of LDL receptors (24), our data show that estradiol replacement therapy has additional beneficial effects on aortic accumulation of cholesterol. This protective effect may be mediated through its action on carbohydrate metabolism, coagulation factors, blood pressure, and prostacyclin/thromboxane balance (25). Furthermore, estrogens may be important for the response of the arterial wall to a given plasma concentration of cholesterol.

Rabbit studies suggest that estrogen affords protection against aortic accumulation of cholesterol (9-12), but in these studies, the number of rabbits was relatively few and hormones

Table IV. Activities of Endometrial Estradioldehydrogenase (EDH) and Isocitratedehydrogenase (ICDH) in the Five Groups

\begin{tabular}{|c|c|c|c|c|c|c|}
\hline & S-PLA & O-PLA & $\mathrm{E}_{2}$ & $\mathrm{E}_{2} / \mathrm{NETA}$ & $\mathrm{E}_{2} / \mathrm{LNG}$ & ANOVA \\
\hline $\begin{array}{l}\mathrm{EDH}\left(n m o l E_{l} / m g\right. \\
\quad D N A / h)\end{array}$ & $\begin{array}{c}36.2 \\
(23-58)\end{array}$ & $\begin{array}{c}12.9 \\
(6.8-25)\end{array}$ & $\begin{array}{c}353.6 \\
(224-558)\end{array}$ & $\begin{array}{c}106.9 \\
(64-179)\end{array}$ & $\begin{array}{c}89.5 \\
(66-122)\end{array}$ & $P<0.0001$ \\
\hline $\operatorname{ICDH}(U / m g D N A)$ & $\begin{array}{c}4.0 \\
(2.6-6.2)\end{array}$ & $\begin{array}{c}0.9 \\
(0.5-1.4)\end{array}$ & $\begin{array}{c}6.3 \\
(4.3-9.1)\end{array}$ & $\begin{array}{c}4.1 \\
(3.1-5.6)\end{array}$ & $\begin{array}{c}4.4 \\
(3.5-5.5)\end{array}$ & $P<0.0001$ \\
\hline
\end{tabular}

Mean (95\% confidence limits). Estriol, $1 \mathrm{nmol} / \mathrm{liter}=27.0 \mathrm{ng} / \mathrm{dl}$. 


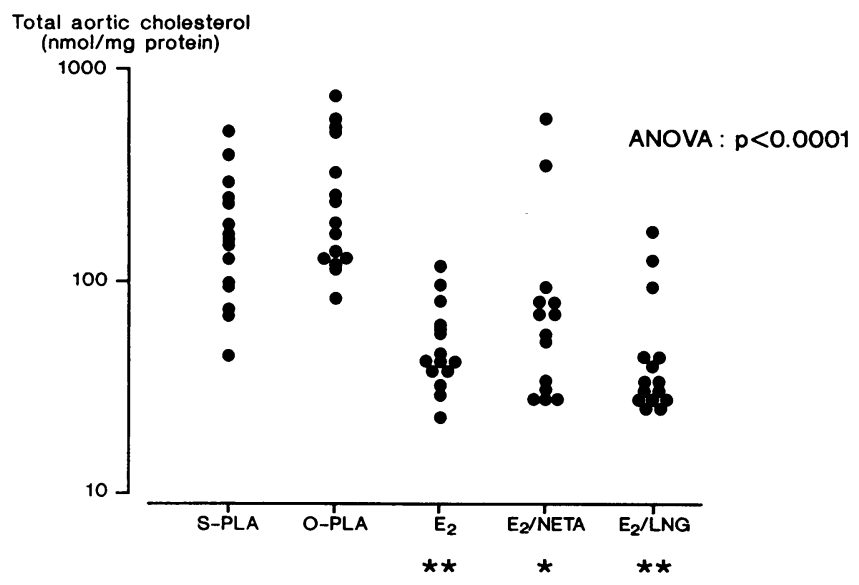

Figure 2. The aortic accumulation of cholesterol in the five groups. The significant differences between the hormone groups and the O-PLA group are visualized by the stars $\left({ }^{*} P<0.001 ;{ }^{* *} P<0.0001\right)$. The differences between the hormone groups and the S-PLA group were virtually similar. There were no statistically significant differences between the hormone groups or between the S-PLA and the O-PLA groups. Cholesterol, $1 \mathrm{nmol}=386 \mathrm{ng}$. were given parenterally (9-12). Studies of cynomolgus monkeys and pigeons also indicate that estrogen administration has a beneficial effect on atherosclerosis $(26,27)$.

The influence of combined estrogen and progestogen therapy on accumulation of cholesterol in the arterial wall has not been investigated before, either in women or in rabbits. Earlier studies of women suggest that 19-nortestosterone derivatives, such as levonorgestrel and norethisterone acetate, reduce or even reverse the beneficial effect of estrogen on HDL cholesterol $(8,28-30)$, considered by some to be the most predictive lipoprotein for atherosclerosis in women (31). These studies suggest that the addition of a progestogen, especially 19-nortestosterone derivatives, may reduce or even reverse the protective effects of estrogen on cardiovascular disease. We found, however, that when given in doses sufficient to affect the endometrium and achieve relevant serum levels, norethisterone acetate and levonorgestrel do not counteract the estrogenic effect on aortic accumulation of cholesterol. Furthermore, the present study indicates that, in addition to its influence on lipid metabolism, estradiol may confer other important benefits. These findings may be important, considering the millions of postmenopausal women who are receiving combined hormone
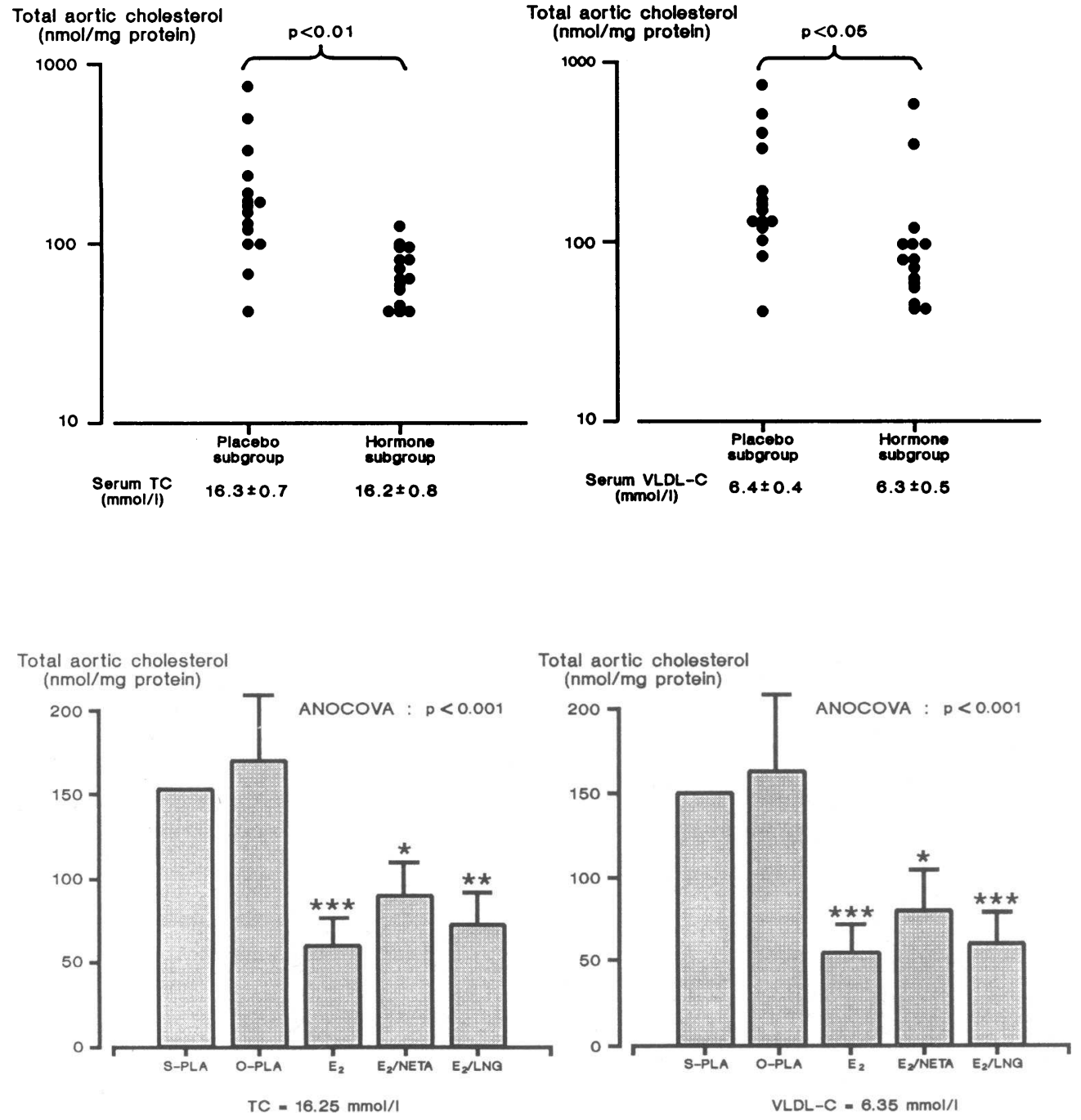

Figure 3. The effect of the hormone treatments on the aortic accumulation of cholesterol, which is independent of serum total cholesterol (left) and serum VLDL cholesterol (right). The upper part shows the results of the two-by-two analysis (selected on the same serum total cholesterol or VLDL-C); the lower part shows the results of the analysis of covariance (ANOCOVA) with $\mathrm{TC}=16.25 \mathrm{mmol} / \mathrm{liter}$ and VLDL-C $=6.35 \mathrm{mmol} /$ liter, $\mathrm{re}$ spectively (mean +1 SEM). The significant differences between the hormone groups and the $O$ PLA group are visualized by the stars $\left({ }^{*} P<0.05 ;{ }^{* *} P<0.01\right.$ $\left.{ }^{* * *} P<0.001\right)$. Cholesterol, 1 $\mathrm{mmol} / \mathrm{liter}=38.6 \mathrm{mg} / \mathrm{dl} ; 1 \mathrm{nmol}$ $=386 \mathrm{ng}$. 
replacement therapy to alleviate climacteric complaints and prevent postmenopausal bone loss.

\section{Acknowledgments}

This work was supported by a grant from Statens Sundhedsvidenskabelige Forskningsråd, Copenhagen, Denmark.

\section{References}

1. Bush, T. L., L. P. Fried, and E. Barrett-Connor. 1988. Cholesterol, lipoproteins, and coronary heart disease in women. Clin. Chem. 34:B60-B70.

2. Ross, R. K., A. Paganini-Hill, T. M. Mack, and B. E. Henderson. 1989. Cardiovascular benefits of estrogen replacement therapy. Am. J. Obstet. Gynecol. 160:1301-1306.

3. Colditz, G. A., W. C. Willett, M. J. Stampfer, B. Rosner, F. E. Speizer, and C. H. Hennekens. 1987. Menopause and the risk of coronary heart disease in women. N. Engl. J. Med. 316:1105-1110.

4. Witteman, J. C. M., D. E. Grobbee, F. J. Kok, A. Hofman, and H. A. Valkenburg. 1989. Increased risk of atherosclerosis in women after the menopause. Br. Med. J. 298:642-644.

5. Stampfer, M. J., W. C. Willett, G. A. Colditz, B. Rosner, F. E. Speizer, and C. H. Hennekens. 1985. A prospective study of postmenopausal estrogen therapy and coronary heart disease. N. Engl. J. Med. 313:1044-1049.

6. Bush, T. L., E. Barrett-Connor, L. D. Cowan, M. H. Criqui, R. B. Wallace, C. M. Suchindran, H. A. Tyroler, and B. M. Rifkind. 1987. Cardiovascular mortality and noncontraceptive use of estrogen in women: results from the lipid research clinics program follow-up study. Circulation. 75:1102-1109.

7. Persson, I., H.-O. Adami, L. Bergkvist, A. Lindgren, B. Pettersson, R. Hoover, and C. Schairer. 1989. Risk of endometrial cancer after treatment with oestrogens alone or in conjunction with progestogens: results of a prospective study. Br. Med. J. 298:147-151.

8. Hirvonen, E., M. Mälkönen, and V. Manninen. 1981. Effects of different progestogens on lipoproteins during postmenopausal replacement therapy. $N$. Engl. J. Med. 304:560-563.

9. Kushwaha, R. S., and W. R. Hazzard. 1981. Exogenous estrogens attenuate dietary hypercholesterolemia and atherosclerosis in the rabbit. Metabolism. 30:359-366.

10. Hough, J. L., and D. B. Zilversmit. 1986. Effect of 17 beta estradiol on aortic cholesterol content and metabolism in cholesterol-fed rabbits. Arteriosclerosis. 6:57-63.

11. Henriksson, P., M. Stamberger, M. Eriksson, M. Rudling, U. Diczfalusy, L. Berglund, and B. Angelin. 1989. Oestrogen-induced changes in lipoprotein metabolism: role in prevention of atherosclerosis in the cholesterol-fed rabbit. Eur. J. Clin. Invest. 19:395-403.

12. Fischer, C. M., and M. L. Swain. 1985. Effects of estradiol and progesterone on the increased synthesis of collagen in atherosclerotic rabbit aortas. Atherosclerosis. 54:177-185.

13. Kaplan, H. M., and E. H. Timmons. 1979. The Rabbit. A Model for the Principles of Mammalian Physiology and Surgery. Academic Press, Inc., New York. 127-129.
14. Byrjalsen, I., B. J. Riis, and C. Christiansen. 1989. The measurement of secretory endometrial protein PP14 in serum from postmenopausal women receiving unopposed estrogen or continuously combined estrogen/progestogen Gynecol. Endocrinol. 3:143-152.

15. Folch, J., M. Lees, and G. H. S. Stanley. 1957. A simple method for the isolation and purification of total lipids from animal tissues. J. Biol. Chem. 226:497-509.

16. Lowry, O. H., N. J. Rosebrough, A. L. Farr, and R. J. Randall. 1951. Protein measurement with Folin phenolreagent. J. Biol. Chem. 193:265-275.

17. Whitehead, M. I., P. T. Townsend, J. Pryse-Davies, T. A. Ryder, and R. J. B. King. 1981. Effects of estrogens and progestins on the biochemistry and morphology of the postmenopausal endometrium. N. Engl. J. Med. 305:15991605.

18. King, R. J. B., M. Whitehead, S. Campbell, and J. Minardi. 1978. Biochemical studies on the endometrium from postmenopausal women receiving hormone replacement therapy. Postgrad. Med. J. 54(Suppl.):65-68.

19. Burton, K. 1956. A study of the conditions and mechanism of the diphenylamine reaction for the colorimetric estimation of deoxyribonucleic acid. Biochem. J. 62:315-323.

20. SAS Institute Inc. SAS/STAT Guide for Personal Computers, Version 6 Edition. SAS Institute, Inc., Cary, NC.

21. Fotherby, K. 1986. Pharmacokinetics of progestational compounds. $\mathrm{Ma}$ turitas. 8:123-132.

22. Wallace, R. B., J. Hoover, E. Barrett-Connor, B. M. Rifkind, D. B. Hunninghake, A. Mackenthun, and G. Heiss. 1979. Altered plasma lipid and lipoprotein levels associated with oral contraceptive and oestrogen use. Lancet. ii:111115.

23. Brattsand, R. 1976. Distribution of cholesterol and triglycerides among lipoprotein fractions in fat-fed rabbits at different levels of serum cholesterol. Atherosclerosis. 23:97-110.

24. Ma, P. T. S., T. Yamamoto, J. L. Goldstein, and M. S. Brown. 1986. Increased mRNA for low density lipoprotein receptor in livers of rabbit treated with $17 \alpha$-ethinyl estradiol. Proc. Natl. Acad. Sci. USA. 83:792-796.

25. Bush, T. L., and E. Barrett-Connor. 1985. Noncontraceptive estrogen use and cardiovascular disease. Epidemiol. Rev. 7:80-104.

26. Clarkson, T. B., M. R. Adams, J. R. Kaplan, C. A. Shively, and D. R. Koritnik. 1989. From menarche to menopause: coronary artery atherosclerosis and protection in cynomolgus monkeys. Am. J. Obstet. Gynecol. 160:1280-1285.

27. Souadjian, J. V., B. A. Kottke, and J. L. Titus. 1968. Estrogen effect on spontaneous atherosclerosis. Arch. Pathol. 85:463-467.

28. Fảhraeus, L., U. Larsson-Cohn, and L. Wallentin. 1983. L-Norgestrel and progesterone have different influences on plasma lipoproteins. Eur. J. Clin. Invest. $13: 447-453$.

29. Jensen, J., L. Nilas, C. Christiansen. 1986. Cyclic changes in serum cholesterol and lipoproteins following different doses of combined postmenopausal hormone replacement therapy. Br. J. Obstet. Gynaecol. 93:613-618.

30. Jensen, J., B. J. Riis, V. Strøm, and C. Christiansen. 1987. Continuous oestrogen-progestogen treatment and serum lipoproteins in postmenopausa women. Br. J. Obstet. Gynaecol. 94:130-135.

31. Gordon, T., W. P. Castelli, M. C. Hjortland, W. B. Kannel, and T. R Dawber. 1977. High density lipoprotein as a protective factor against coronary heart disease. Am. J. Med. 62:707-714. 